\title{
Participación política de los indígenas del Cauca como construcción de ciudadanía
}

\author{
Political participation among indigenous people \\ from Cauca as a way of building citizenship
}

\begin{abstract}
William Andrés García Cifuentes ${ }^{1}$
wgarcia2@funandi.edu.co

\section{Resumen}

Este artículo trata sobre la problemática de la participación política de los grupos indígenas en el suroccidente colombiano, haciendo principal referencia a las comunidades del norte del Cauca, teniendo como marco principal el municipio de Toribio. En este sentido, la participación indígena es analizada desde diferentes elementos abordados como: las dimensiones histórico-culturales, políticas y económicas que los motivaron a realizar una movilización colectiva, un diagnóstico del conflicto armado, y el modelo de cabildo urbano en Santiago de Cali, así como sus procesos de consolidación y construcción de paz desde la participación local. Con ello se busca elaborar unas conclusiones básicas para una mayor compresión de las dinámicas políticosociales de esas comunidades.
\end{abstract}

\section{Palabras claves}

Participación política, territorio, resguardo, cabildo, actores armados, norte del Cauca.

\section{Abstract}

This article deals with the predicament of the Political Participation of Indigenous Groups in Southwest Colombia, by making mainly a reference to the northern communities of Cauca province, and framing it particularly around the Toribio municipality. Thus, Indigenous Participation is analyzed from different perspectives and elements such as: historical-cultural dimensions, political and economical, that motivated them to organize a colective mobilization, a diagnosis of the armed conflict, and the urban town council model in Santiago de Cali, as well as processes of peace consolidation and construction based on local participation. With this I seek to elaborate some basic conclusions for a better comprehension of the political-social dynamics in these communities.

\section{Keywords}

Political participation, territory, shelter, town council, armed actors, northern Cauca.

Forma sugerida de citar: GARCÍA CIFUENTES, William Andrés (2013). "Participación política de los indígenas del Cauca como construcción de ciudadanía". En: Universitas, XI (19), julio-diciembre, p. 217-236. Quito: Editorial Abya Yala/Universidad Politécnica Salesiana.

1 Politólogo de la Pontificia Universidad Javeriana, Cali. Candidato a magister en Gestión Pública, director Ejecutivo y representante legal de la Escuela de Gobierno y Gestión Pública, director del Programa de Ciencias Políticas de la Facultad de Ciencias Jurídicas, Sociales y Humanísticas de la Fundación Universitaria del Área Andina Pereira-Risaralda. 


\section{Introducción}

Este artículo es producto de una investigación y seguimiento de los acontecimientos realizados en la ciudad de Santiago de Cali, desde el mes de septiembre de 2004, más específicamente las manifestaciones multitudinarias y la llegada de la marcha indígena procedente del departamento del Cauca, el día 13 del mismo mes, así como la "cruenta toma de grupos al margen de la ley" en el municipio de Toribio y algunas veredas aledañas el 14 de abril del 2005 en el departamento del Cauca.

De esta manera se decidió documentar el proceso de movilización y la acción colectiva de las diversas etnias y la participación indígena en todos sus aspectos: político, cultural, social y económico. Asimismo, se logró generar confianza con comunidades indígenas que se encuentran en la ciudad, pertenecientes a algunos resguardos del departamento del Cauca y que se han asentado durante los últimos años en el municipio de Santiago de Cali.

El objetivo de este artículo, es analizar la participación política de las comunidades indígenas en el sur occidente de Colombia, a través de su organización y modelo de acción colectiva, tomando como referencia el cabildo, como la "entidad pública especial, cuyos miembros son indígenas elegidos y reconocidos por una parcialidad localizada en un territorio determinado, encargado de representar legalmente a su grupo y ejercer las funciones que le atribuye la ley y sus usos y costumbres"3. Los cabildos del norte del departamento del Cauca y el cabildo indígena de Santiago de Cali, son los que representan uno de los mayores índices de participación política en nuestro país. Adicional a esto, analizar la consolidación de los procesos sociales y de desarrollo comunitario, partiendo de un diagnóstico del conflicto armado y modelo de desarrollo local que ejecutan estos pueblos para su conservación y para su integración dentro de las dinámicas sociales del Estado-nación.

La investigación y los avances obtenidos para la ejecución de este trabajo se realizaron en los meses siguientes a la marcha indígena en septiembre de 2004, así como la toma del municipio de Toribio por parte de las FARC. De esta ma-

2 Incursión armada de grupos guerrilleros (FARC).

3 Publicada en el Registro Oficial No 42.140 del 7 de diciembre de 1995, decreto 2164, art. $\mathrm{N}^{\circ} 2$. 
nera se considera que aún falta desarrollar y conceptualizar la documentación de las diferentes actividades y procesos indígenas que cada día van tomando más fuerza dentro de la región y la ciudad, ampliando el conocimiento de los ciudadanos en la interacción y el respeto por la diferencia que posee nuestra urbe.

Hay que resaltar que la documentación obtenida fue escasa y difícil de encontrar, porque estas comunidades no acostumbran a mostrar a personas ajenas los procesos que se manejan dentro de los resguardos, por lo tanto la gran mayoría de la bibliografía es tomada de periódicos locales y nacionales, de folletos, panfletos y volantes obtenidos en cada una de las actividades asistidas, así como de programas de radio y televisión; además de algunas entrevistas que fueron realizadas a diferentes personas de las comunidades indígenas.

La metodología empleada en la realización de este documento constituye el desarrollo de varios puntos importantes para comprender la participación política de los pueblos indígenas, basada en el aspecto sociocultural. Primero, se dará énfasis a las dimensiones que los impulsa a pedir cambios drásticos en la manera de ver las comunidades. En segundo lugar, se enfocará el conflicto armado que se presenta en la zona. Tercero, se dedicará a la forma de participación del cabildo urbano Yanacona, en la ciudad de Santiago de Cali y los obstáculos presentados para la consolidación de los procesos, haciendo una referencia particular en el proceso vivido en la ciudad de Santiago de Cali con la creación del cabildo indígena municipal Yanacona. Por último se hablará del proceso de construcción de la paz desde la participación local.

\section{La participación política de los pueblos indígenas del norte del Cauca como elemento constructor de ciudadanía activa en Co- lombia}

El municipio de Toribio, cuna de movimientos de resistencia pacífica a los violentos, un poblado de mayoría indígenas ubicado en un pequeño valle entre las montañas de la cordillera central, al norte del departamento del Cauca, con 32.673 habitantes en su casco urbano y áreas rurales, lugar de la constitución de unas de las organizaciones étnicas más fuertes de América Latina y con mayor recono- 
cimiento a nivel internacional, como es el CRIC, ${ }^{4}$ cuna de la filosofía del padre Álvaro Ulcué Chocue, ${ }^{5}$ territorio azotado por más de 11 tomas guerrilleras, así como escenario de paz en el armisticio del movimiento 19 de Abril. ${ }^{6}$ Se trata de un territorio que ha recibido el reconocimiento de los organismos internacionales por su organización, su guardia indígena y sus diversos procesos sociales. Todo ello hace de Toribio una población más que especial en nuestra geografía colombiana.

Toribio, que en lengua de origen se traduce como "tierra de la plata y el licor", en los últimos dos años ha estado inquieta no solo por las diferentes fiestas de "mingas, tulpas y quilombos", sino por las diferentes manifestaciones sociales en torno a los casos de violencia vividos, tales como los secuestros de líderes políticos ${ }^{7}$ y asesinatos selectivos que se presentaron en la región y que han provocado que las comunidades se movilizaran.

Una movilización tan masiva como histórica en Colombia la registraron los medios, por primera vez, en la ciudad de Santiago de Cali, que fue tomada de forma pacífica por 60.000 indígenas caminantes de distintos sitios del territorio caucano, siendo apoyados por otros resguardos en el valle del Cauca que, ingresando a la ciudad por unas de las vías de mayor afluencia, llegaron para acantonar en los predios del velódromo Alcides Nieto Patiño en pleno corazón de la sultana del valle.

Pero la movilización social no responde a un simple acantonamiento ni una integración pluricultural y multiétnica, responde a un llamado de atención al Gobierno por el abandono en que tiene sumida a las comunidades indígenas, por los procesos de violencia y conflicto armado que se viven en los territorios, por las pérdidas de espacio territorial a causa de terratenientes y narcotraficantes, quienes son los mayores causantes del desplazamiento forzoso y la extrema

4 El Comité Regional Indígena del Cauca nació el 24 de febrero de 1971 con tres objetivos: luchar por la autonomía, recuperar las tierras y el fortalecimiento comunitario.

5 Sacerdote indígena de los Paeces y padre de la resistencia pacífica, asesinado en Santander de Quilichao, el 10 de noviembre de 1984. Tal liderazgo es hoy inspirador para diversos proyectos que se gestan a su nombre, así como diversas instituciones que hoy llevan su nombre como eje emblemático.

6 En la vereda de Santo Domingo, el 9 de marzo de 1990, se firmó la entrega de armas y desmovilización del M-19, frente al movimiento Carlos Pizarro Leongomez.

7 Mas exactamente, el secuestro de Arquímedes Vitonás y otro líder comunal y varios asesinatos selectivos como el ocurrido en Santander de Quilichao con el líder yanacona y su hijo de tan solo 13 años, sacados de su casa en el casco urbano y abaleados. Este último caso se encuentra sin esclarecer por parte de las autoridades competentes. 
pobreza, y por las decisiones económicas que toma el Gobierno sin tener en cuenta algunas subregiones. Es por ello que se han identificado unas dimensiones o motivaciones centrales para la movilización colectiva que se presentó en el mes de septiembre de 2004.

En muchas ocasiones los indígenas, los trabajadores, los campesinos, los afrodescendientes, los sindicalistas, hombres, mujeres y demás organizaciones sociales y gremiales de Colombia, nos hemos unido para luchar por la reivindicación de nuestros derechos buscando encontrar la posibilidad de una vida digna [...]. Como ustedes saben y conocen lo que sucede hoy en nuestro país y en nuestros territorios es grave, no da espera y debemos actuar rápido y de manera urgente. La crítica situación que vivimos los excluidos, se debe a un problema de fondo relacionado con la estrategia Neoliberal y la Globalización, y por eso cualquier acción que hagamos ahora, hará parte de una lucha a mediano y largo plazo. Hoy no solo son nuestros derechos los que están en peligro compañeros, es la Vida misma la que está en riesgo. Por eso hoy más que nunca nos debe convocar a todos la Unidad, la Solidaridad y la Dignidad para defender lo que es nuestro. Este país es de nosotros y es hora de reclamarlo (fragmentos de los discursos de los cabildantes en la movilización indígena de 2004).

En la motivación central para la participación en la marcha indígena podemos analizar cuál es el fondo real de la movilización de las comunidades, además de su preocupación constante por la supervivencia, que se refleja en una lucha inquebrantable por la vida. Esta motivación podemos verla expresada en tres categorías o dimensiones: 1) dimensión histórico-cultural, 2) dimensión política y 3) dimensión económica.

\section{Dimensión histórica y cultural}

Cabe resaltar que Colombia es un país que posee múltiples etnias y de una riqueza cultural envidiable, tradiciones ancestrales, que por muchos años han permanecido en las memorias de las comunidades. En este caso son los pueblos indígenas que han podido mantener su cultura a través de miles de años, logrando sobrevivir a diversos sistemas de gobierno. Como primer elemento histórico-cultural, fue fundamental la construcción de sus propios sistemas de 
gobierno basados en lo comunitario, como segundo aspecto de importancia, el aporte en la construcción del cabildo donde se referencia la época de la Conquista y por último la construcción de una república, que concebía la unidad del pueblo colombiano en una sola raza, lengua, religión y cultura.

Todas estas transformaciones han hecho que las comunidades indígenas se levanten en contra del exterminio cultural, exigiendo el retorno de sus tierras ancestrales para la consolidación de sus identidades. Es por esto que los pueblos indígenas vienen desde tiempos inmemorables en una lucha constante con el Estado para ser reconocidos como seres autónomos, con una cultura e historia propias. Podríamos recordar las expresiones indígenas durante el inicio del siglo XX, con el líder indígena Manuel Quintín Lame, ${ }^{8}$ que luchó por los derechos de los indígenas, sobre los resguardos y la oposición a la extensión del latifundio. De ahí en adelante la lucha indígena por la reivindicación de sus derechos ha sido constante desde los años 70; aun en la actualidad se han venido realizando movilizaciones y resistencias sociales no solo contra la falta de garantías y legitimación de las políticas del Estado, sino también contra los grupos alzados en armas que perturban la paz de las comunidades.

\section{Dimensión política}

Desde el punto de vista político, las comunidades indígenas poseen posturas filosóficas basadas en las ideologías ancestrales y naturales. Las comunidades permanentemente realizan reuniones o mingas donde todos los individuos pertenecientes al cabildo asisten para discutir sobre hechos o sucesos que les afectan, así mismo ver estos entramados sociales debidamente organizados discutiendo y dialogando sobre propuestas y posibles proyectos son desde el punto de vista académico: relaciones políticas. Max Weber, en "El político y el científico" dice: "el político debe vivir de y para la política". Los líderes cabildantes (gobernadores, alcaldes, alguaciles, comuneros, guardias indígenas y líderes espirituales o the wala `s) que se encuentran al servicio de la comunidad y serán

8 Líder indígena de una comunidad de Tierradentro, del departamento del Cauca. Sirvió de inspiración para que naciera con sus ideales un movimiento político. 
sostenidos económicamente por el cabildo o resguardo al que pertenecen, su condición política los responsabiliza.

Las motivaciones políticas están actualmente ligadas con las amenazas o “atentados" contra sus pueblos y tradiciones. En necesario plantear aquí dos de los tres aspectos esenciales que durante la movilización indígena se vociferó:

El primero [...] las violaciones y el irrespeto a los derechos humanos y a la vida se evidencia con el ataque más notorio, en los asesinatos y secuestros selectivos de líderes indígenas cometidos por las FARC o los paramilitares, que los convierten en blancos militares de una guerra de la que ellos no son parte. Y el segundo aspecto es la contrarreforma constitucional que impone el Gobierno nacional para entregarle el país y su gente a intereses económicos globales. ${ }^{9}$

\section{Dimensión económica}

Este tipo de dimensión no se refiere a ventajas económicas ni a la adquisición de dineros, se refiere a la preocupación que tienen los indígenas con respecto a las reformas económicas que están en proceso de negociación con Estados Unidos -el Tratado de Libre Comercio (TLC) y Área de Libre Comercio de las Américas (ALCA)- que según los indígenas pondrían en riesgo la propiedad comunitaria, que por su mismo nombre no se puede negociar. En su concepción ancestral, ni ellos ni nadie es dueño de la tierra, por el contrario, somos todos los que le pertenecemos a la tierra. Es por esto que se niegan a acuerdos y negociaciones sobre ella. Usando sus propias palabras:

Cuando lo firmen, nada será nuestro [...]. Nada [...]. Para empezar, quieren patentar toda la vida en este país para hacer un negocio con ella. Hoy ni lo que comemos, ni la tierra donde nacimos y vivimos, ni nuestros hijos, ni nosotros mismos convertidos en esclavos y extranjeros en nuestro país, ya no seremos libres, seremos propiedad de las multinacionales. ${ }^{10}$

9 Palabras del líder indígena mediante el perifoneo a bordo de una camioneta, motivando a los caminantes indígenas y a la ciudadanía que escucha y ve la movilización de septiembre de 2004.

10 Folleto "Vamos todos al congreso de pueblos indígenas, campesinos y trabajadores. Vamos... ipero vamos ya!". 
Frente a estas tres dimensiones se crean en las comunidades una cultura de organización, para generar una conciencia crítica frente a obstáculos estructurales e ideológicos que les permite una discusión de problemas que les pueda afectar directamente en ellos, es así como se generan unas condiciones de participación evidentes en el texto de Hopenhayn. ${ }^{11}$ En eso la Universidad Indígena ha sido fundamental en la enseñanza del derecho propio, no dejando perder su cultura mediante la etnoeducación. De esta manera se fortalece su participación en diferentes ámbitos, no solo lo político, sino también lo sociocultural, logrando una integración de todos los habitantes de los resguardos a participar en la toma de decisiones que le conciernen y le afectan a todos. Es de admirar el modelo de participación de los indígenas, por la característica de inclusión tanto de niños como de ancianos, permitiendo una legalidad y legitimidad de sus propias organizaciones.

La participación de los indígenas en la construcción de nuevas soluciones para sus resguardos, permite el fortalecimiento de sus propias estructuras internas y una interacción directa con los cabildos a través de diferentes proyectos que buscan el mejoramiento de las condiciones de vida por sus propios medios. Esto se dada a raíz del abandono del Estado con estos pueblos.

\section{Diagnóstico del conflicto armado}

Las comunidades indígenas desde tiempos inmemoriales han venido en una lucha constante por el respeto de sus derechos en especial el derecho a la vida, sin embargo, desde enero de 1987, el norte del Cauca, más exactamente Toribio, ${ }^{12}$ ha sido epicentro de las más cruentas tomas guerrilleras de la historia llevadas a cabo por el sexto frente de las FARC. Esa acción violenta se ha repetido once veces por parte de distintos grupos armados, entre ellos el M-19,

11 Martín Hopenhayn plantea la participación y sus motivaciones, así como las condiciones reestructurales para la participación.

12 Municipio del norte del departamento del Cauca, de mayoría indígena, cuyo cabildo más importante es el Nassa-Páez. Su desarrollo se basa en un proyecto denominado Plan de Vida. 
el ELN, el Frente Ricardo Franco, ${ }^{13}$ el Movimiento Quintín Lame ${ }^{14}$ y el Movimiento de Jaime Bateman, así como irrupciones en parcelas de los cabildantes de pequeños ejércitos de hombres pagados por terratenientes y narcotraficantes. Fue así como el 16 de diciembre de 1991 enlutaron el pueblo Nassa-Páez con el asesinato de 21 integrantes del resguardo en la hacienda El Nilo, ubicadas entre los municipios de Caloto y Toribio.

La última toma al municipio de Toribio ${ }^{15}$ tuvo un saldo de 3.500 millones de pesos en pérdidas materiales, así como un desplazamiento forzoso de 3.000 personas, además de perdidas económicas en cultivos, animales y empréstitos nacionales y extranjeros, sin contar que afectó a 63 veredas, pertenecientes a 4 resguardos con un total de 116 cabildos perturbados por la incursión. ${ }^{16}$ Mucho después de la incursión guerrillera se publicó en un diario de amplia circulación que:

El ataque de la guerrilla se pudo evitar, según un documento de la Defensoría del Pueblo, el 13 de mayo de 2004, el sistema de alertas tempranas de ese despacho envió un informe del riesgo en el cual se advertía lo que posiblemente sucedería si no se tomaban medidas. En ese mismo documento también se advertían que las comunidades indígenas son vistas por la FARC como grupos contrarios a sus intereses por las actitudes de resistencia civil (El Espectador, 2005).

De igual forma y hasta la fecha, esta situación la siguen viviendo las comunidades del norte del Cauca, que por intereses de los grupos armados los convierten en víctimas del fuego cruzado.

Ellos tienen que convivir con las tensiones, señalamientos y acusaciones provenientes de los bandos del conflicto. Además del constante asedio de los distintos actores armados que pretenden convertirlos en seguidores-militantes o en par-

13 El Frente Ricardo Franco tuvo como cabecilla a José Hedor Rey alias "Javier Delgado", quien autoeliminó el movimiento y asesinó a garrote, en las montañas de Tacueyo, corregimiento de Toribio, en 1987, a 164 de sus militantes acusándolos de infiltrados del ejercito.

14 El 31 de mayo de 1991 el movimiento Quintín Lame depone las armas en el municipio de Caldono.

15 El 14 de abril de 2005 fue intenso, según versiones de los indígenas entrevistados, pues el ejército tardó dos días en ingresar al casco urbano y se dedicó a repeler el ataque desde helicópteros artillados y el avión fantasma.

16 Datos suministrados por la ACIN (Asociación de Cabildos del Norte del Cauca). 
te de la Fuerza Pública, con el programa llamado Soldados Campesinos, ${ }^{17}$ así como en combatientes de sus causa ideológicas. ${ }^{18}$

Las fuerzas armadas son consideradas por los líderes indígenas como una de las partes que promueven y profundizan el conflicto armado, por ende en distintas situaciones han solicitado el retiro de la zona, sin que se hayan tenido éxito y como respuesta el presidente de la república (Álvaro Uribe) ordenó continuar los operativos al mando del general Ospina, ${ }^{19}$ dando sentido al manifiesto democrático y más exactamente al punto sobre seguridad democrática. Sin embargo, para Alfredo Rangel, ${ }^{20}$ "las operaciones militares cayeron en un $10 \%$, por efecto del plan patriota. ${ }^{21}$ Pero también el $10 \%$ de la tropa del ejército está concentrada en Caquetá, Meta y Gaviare". Además, Rangel asegura que si existe una estrategia de la guerrilla y es salir del sitio de la ofensiva para atacar en otros puntos y luego, salir del punto y así circularmente (El Tiempo, 24/04/2005).

Es así que actualmente en las zonas de ubicación funcionan diversos grupos de la fuerza pública para contrarrestar la oleada terrorista. Entre ellos están la recién creada Brigada 29 cuya influencia abarca los departamentos del Cauca y Nariño, ${ }^{22}$ con el apoyo de 5 batallones de la región, 1 grupo de asalto de las Fuerzas Especiales Contraguerrillas N 57 de Jamundi, el Grupo de Apoyo Meteoro, Héroes de Iscuandé en el Pacífico y el Grupo Macheteros de Piendamo. ${ }^{23}$

17 Después del 30 de abril se empezaron a transmitir desde estaciones radiales de Popayán y Palmira, mensajes en lenguas nasa yute y naway wan. La motivación era la incorporación de indígenas como soldados campesinos o a la red de cooperantes, estrategia que preocupa al CRIC, por poner en peligro a los nativos y obligarlos a involucrarse en el conflicto armado. El CRIC señala que las lenguas maternas representan sabiduría y conocimiento de los pueblos indígenas.

18 Tomado del XI informe del Defensor del Pueblo al Congreso de Colombia (2003: 96).

19 Comandante general de las Fuerzas Militares en Colombia, entre el año 2004 y 2007.

20 Analista político y director del Centro Seguridad y Democracia de la Universidad Sergio Arboleda; columnista de la revista Semana.

21 Nombre dado por las fuerzas militares a los operativos contra grupos insurgentes en el territorio nacional a partir del año 2003.

22 Zonas de mayor asentamiento de poblaciones étnicas, es su mayoría indígenas y campesinos.

23 Datos de conocimiento público suministrados por la Tercera Brigada. 
Para darnos cuenta de la verdadera realidad que se vive en nuestra nación con relación a los pueblos indígenas, un programa de televisión resume los actos de desplazamiento y violencia suministrando los siguientes datos así:

El himno Nassa recuerda a Álvaro Ulcué Chocue, asesinado el 11 de noviembre de 1984 cuando lanzaba su proclama "Gente para la tierra". En 2004, 17 comuneros indígenas han sido asesinados por las FARC, los paramilitares han cometido masacres en las veredas de Corinto, Caloto y Caldono, en la Guajira los "paras" han desplazado y asesinado a decenas de indígenas, a nivel nacional 83 indígenas han sido asesinados en 2004 y 3.496 fueron desplazados [...]. Por el derecho a la vida marchan [...] siempre recordando a los líderes caídos y que una vez soñaron una Colombia más justa, más incluyente. ${ }^{24}$

Aun en medio del conflicto, han logrado articular procesos de organización social con directrices claras sobre qué hacer, antes, durante y después de atentados, tomas o incursiones armadas, es así como se creó el Plan de Emergencia y Resistencia, el cual determina qué hacer en medio del conflicto. ${ }^{25}$

En nuestra nación, la existencia de normativas constitucionales y la aceptación de normas e instrumentos internacionales de los pueblos indígenas en el marco de la protección de grupos étnicos y raizales, no es suficiente. Los datos anteriores demuestran la incapacidad del Estado, la insatisfacción de los pueblos indígenas y las continuas muertes. Incluso en la actualidad hay casos suscitados con los líderes políticos y espirituales (uno en el departamento del Cauca con el líder yanacona y su hijo y otro con el líder espiritual en la Sierra Nevada de Santa Marta), ambos asesinados en la impunidad. Sin embargo, aunque las leyes plasmadas en el papel no sean ejecutadas y controladas por el Estado y mucho menos respetadas por diversos grupos insurrectos, son múltiples los esfuerzos por contrarrestar la posible extinción de nuestro patrimonio cultural.

El tema de las normas e instrumentos internacionales adquiere gran importancia. Son los diversos estamentos u órganos de las Naciones Unidas las abanderas en la protección de grupos étnicos y raizales. Dentro de las normativas del

24 Estas notas son del programa de tv Primer Orden, del canal 8: "Marcha y violencia indígena".

25 Testimonio de Jorge Arias, representante consejero de la Asociación de Cabildos del Norte del Cauca, haciendo alusión al Plan de Vida o plan de desarrollo de los municipios indígenas. 
derecho internacional se abordan temas de derecho de indígenas. Además, en un marco más general, en la Declaración de los Derechos Humanos, adoptada en 1948, se tiene dos principios: la igualdad y la no discriminación.

Algunos pueblos indígenas víctimas del genocidio cultural o etnocidio, han apelado a la comunidad mundial y a la ONU para la aplicación de la Convención para la Prevención y Sanción del Delito de Genocidio de 1948, así como el Pacto Internacional de Derechos Económicos, Sociales y Culturales, y el Pacto Internacional de Derechos Civiles y Políticos, ambos adoptados en 1966, pero que solo entraron en vigor en 1976. En ellos se prohíbe la discriminación basada en la raza, sexo, color, religión, lengua, origen social o nacional, propiedad o el nacimiento. Añadiéndose así la Convención sobre la Eliminación de todas las Formas de Discriminación Racial, adoptada en 1965.

Sin embargo, ninguno de estos pactos, convenciones, tratados y derechos se refieren directamente a los derechos indígenas, pero son los que más comúnmente son invocados, como también se han tomado medidas para la protección y derechos de los pueblos indígenas bajo las normas contenidas en los instrumentos internacionales de derechos humanos aplicables al tema de los pueblos indígenas. ${ }^{26}$

En la actualidad existe una lucha por la concepción de la justicia en las comunidades indígenas, entre los organismos que defienden los derechos humanos y el DIH y la sabiduría ancestral para aplicar la justicia. A esto los indígenas argumentan que los conceptos de libertad son diferentes de los de la cultura occidental. Para ellos:

La libertad depende de cómo funciona la comunidad, nada está separado como una "cómoda". De este lado está la moral, de este otro el castigo y más allá la ley [...]. Así que si se infringe una ley de la naturaleza, por ejemplo, tiene que ser castigado, y es la propia comunidad que pone el castigo [...], esta es nuestra

26 Declaración Universal de los Derechos Humanos, art. 7 y 17. Declaración Americana de los Derechos y Deberes del Hombre, art. II. Pacto Internacional de Derechos Civiles y Políticos, art. 2, 26 y 27. Pacto Internacional de Derechos Económicos, Sociales y Culturales, art. 13. Convención sobre los Derechos del Niño, art. 30. Convención Americana sobre Derechos Humanos, art. 1. Convenio Sobre Diversidad Biológica, art. 8. Convenio No 169 de la OIT sobre Pueblos Indígenas y Tribales en Países Independientes. Convenio Internacional sobre la Eliminación de todas las Formas de Discriminación Racial. Declaración sobre los Derechos de las Personas Pertenecientes a Minorías Nacionales o Étnicas, Religiosas y Lingüísticas. Proyecto de Declaración de las Naciones Unidas sobre los Derechos de las Poblaciones Indígenas. Proyecto de Declaración Americana sobre los Derechos de las Poblaciones Indígenas. 
diferencia con los DIH [...]. En cuanto a las sanciones de justicia a latigazos, las comunidades lo han asumido como propias [...], pero esto no pertenece a la tradición histórica de los pueblos, los españoles fueron quienes implementaron este modelo. $^{27}$

Para poder comprender los modelos de justicia es importante saber que las tradiciones y la cultura de un pueblo no pueden ser transformadas, con la implementación de modelos ajenos a su tradición, por lo tanto es complejo tratar de imponer una carta de derechos humanos cuando ellos ya aplican principios "naturales" y comunitarios desde sus ancestros. Estos son los principios indígenas "el ama chuga, ama quella, ama yuya" (no robarás, no mentirás, no serás haragán). ${ }^{28}$

Aunque la Constitución de Colombia de 1991 permite la participación indígena para su representatividad en las instancias del poder político, hay que resaltar que estas comunidades, no están de acuerdo con las afiliaciones partidistas, por lo tanto los indígenas que aspiren a ocupar cargos públicos deben tener el aval indígena y de ninguna manera haber o pertenecer a un partido político. ${ }^{29}$ En palabras de Ari Campo Chicangana: "las comunidades no pertenecen a los partidos políticos porque pueden ser objeto militar [...] esto puede ser una de las consecuencias de las muertes de los dirigentes indígenas además de los intereses del Estado y las multinacionales". A pesar de todo, las comunidades poseen no partidos pero sí organizaciones que se comunican con el Gobierno. Es el caso de la Alianza Indígena, que nace de las comunidades indígenas y se abre al país como una alternativa pacifica para solucionar los problemas de este sector de la población colombiana. Para condenar la politiquería y los partidos tradicionales o a los que se hacen llamar liberales indígenas. Las poblaciones indígenas quieren dejar claro que ellos no son partidarios ni de conservadores, ni de liberales, ni mucho menos de la izquierda con el polo democrático.

Durante diez años a causas del conflicto en mayor medida se desplazaron hacia Cali provenientes de las zonas de sur y occidente de Colombia y más

27 Entrevista a Ari Campo Chicangana, en la Loma de la Cruz, cabildo urbano Yanacona, de la ciudad de Cali.

28 Entrevista a Giovanny Yule, representante legal de la ACIN y aspirante a la dirección del CRIC.

29 Es el caso del gobernador del departamento del Cauca, Floro Tunubalá, indígena perteneciente a la comunidad Guambiana. 
exactamente de los departamentos del Cauca, Nariño, Putumayo y Choco. Todos pertenecientes a diversas etnias y culturas. Empezaron a consolidar un proceso de conformación de cabildo urbano para no perder su condición étnica y para preservar su cultura. Sin embargo, ese proceso se ha visto estancado por la poca representación de líderes étnicos en cargos nominales y plurinominales, dado que partidos políticos que se dicen ser de carácter étnico y promulgan la igualdad, carecen de representación y propuestas desde las mismas comunidades.

\section{Participación del cabildo urbano de Santiago de Cali: obstácu- los presentados para su consolidación}

La organización del cabildo indígena urbano, inicio su proceso de creación desde 1989 y se concretó en 1999, con la construcción del cabildo y su reconocimiento por parte del municipio de Santiago de Cali. Para Ari Campo, integrante del cabildo y promotor del proceso, "el reconocimiento de los cabildos hay que ponerlo en duda, ya que es lastimoso ver que las comunidades indígenas tengan que ser reconocidas, por estas autoridades, cuando ya están fijadas por el derecho propio o derecho mayor". El motivo principal que incitó para la creación del cabildo, fue la gran cantidad de población indígena que inmigró a la ciudad durante estos años, y que hasta la fecha no ha parado. Este problema se debe a que las poblaciones han aumentado demográficamente, pero los resguardos no, ellos son pequeños en relación a la época colonial en que fueron asignados.

Antes de la creación del cabildo urbano, en la ciudad ya había una primera conformación de un cabildo: El INGA, pero este carecía de una organización fuerte, carecía de un reconocimiento por parte de la ciudadanía y carecía, al mismo tiempo de una difusión clara de sus demandas y de su posición frente a la ciudad. De esta manera se piensa en la conformación del cabildo urbano, trabajando fuertemente en el fortalecimiento de su organización, y la difusión, apelando a los medios de comunicación para que exista en la ciudad ese reconocimiento que hacía falta.

Es por esto que se realiza un primer acercamiento a la comunidades indígenas que se encontraban en la ciudad a partir de una convocatoria para la 
conformación del cabildo, Una de las motivaciones para la conformación del cabildo fue el terremoto de Armenia, que afecto en gran medida las comunidades yanaconas y otras etnias del Eje Cafetero. Se pensaba que en Cali podía suceder lo mismo, por tanto había que empezar a trabajar. Se convocó a la gran mayoría de los indígenas que habían inmigrado a Cali, entre ellos los de Río Blanco, Wachicanó, Kakiona y San Sebastián. Esto atrajo un aproximado de 700 indígenas yanaconas para la elección y el censo del cabildo. La cantidad de indígenas asentados en la ciudad trajo como consecuencia la primera dificultad para el naciente cabildo, ya que no se pudieron realizar las elecciones hasta que no se terminara el censo. Terminado el estudio, este arrojó un total de 1.200 indígenas asentados en la ciudad, cifra que se mantiene a la fecha aunque con una particularidad: no hay homogeneidad de etnias, existen cabildos asentados de otros departamentos como de Risaralda, Quindío, Choco y Nariño. A ellos se suman ciudadanos incluso de Ecuador, conocido por su gran cantidad de pobladores (como los otavaleños) dedicados a la venta de artículos tejidos y asentados la zona centro de Cali.

Hasta antes de 2003 se había venido trabajando en el reconocimiento de la comunidad indígena en la ciudad, con múltiples procesos truncados por las anteriores administraciones municipales, que no reconocían la conformación de los cabildos indígenas y su participación significativa en las dinámicas del Estado (ley 89 de 1890 y la constitución de 1991). Solo hasta noviembre de 2003 y finalizando la administración del alcalde Jhon Maro Rodríguez, se reconocen a las comunidades indígenas de Cali dándoles personería jurídica.

En la actualidad, la ciudad de Cali tiene cinco cabildos: el Yanacona, el Inga, el Kichua, el Nassa, el Guambiano y dos en proceso de formación los Kofanes pertenecientes a la Amazonía y los Pastos que es una mezcla entre indígenas y campesinos pertenecientes al sur de Colombia, concretamente, al departamento de Nariño. En cuanto al proceso de participación y de integración con el municipio, los cabildos se encuentran trabajando junto con el municipio de Santiago de Cali en unas mesas de concertación, tratando de implementar en los diferentes planes, programas y proyectos la política municipal indígena, concertada en unas premesas sobre las necesidades básicas de las comunidades que habitan el área urbana del municipio. 
Fue así como la municipalidad aceptó la existencia y conformación de los cabildos en la ciudad de Santiago de Cali, lo cual condujo a que se pensara en unas políticas indígenas propias de los cabildos, asimismo, el naciente cabildo dentro de su plataforma política identificó la necesidad de representación ante las diferentes corporaciones públicas de la municipalidad.

\section{Política indígena municipal de Santiago de Cali}

La creación de una política indígena municipal permitió abrir los espacios de integración de las comunidades con el municipio, de manera que se pudieran estudiar sus condiciones de vida y crear mecanismos para la solución a los problemas que les concierne. Esta política fue creada en conjunto a través de la participación de las comunidades indígenas y la administración pública, y se trata de cuatro aspectos fundamentales que les garantiza a las comunidades su convivencia, la supervivencia de su cultura, los derechos estipulados en la Constitución de 1991, su autonomía como pueblos y una vida digna.

El primer aspecto a tocar de la política es la educación: la tienen las comunidades para sus cabildantes, la idea de este punto de la política no es aislarse, sino crear una educación pluricultural abierta a la comunidad, instituciones que por sus rasgos orienten sus proyectos pedagógicos de aula, a la enseñanza de las diversas etnias.

El segundo aspecto es la salud: el derecho a la salud está garantizado a través de una ARS indígena, ${ }^{30}$ pero aún se sigue discutiendo la búsqueda de una salud integral, basada en la medicina tradicional indígena. En este punto el Estado emitió la ley 691 de 2001 que reglamenta el derecho a la salud y seguridad de los pueblos indígenas de Colombia, incorporando los principios de la diversidad étnica y cultural como ejes rectores de la política de salud que el Estado debe garantizar a los pueblos indígenas. ${ }^{31}$ Pero falta aún involucrar dentro de este estatuto el carácter de atención integral que reconozca las condiciones culturales, el manejo botánico y espiritual de la salud.

30 Administradoras del Régimen Subsidiado Indígenas.

31 Tomado del XI informe del Defensor del Pueblo al Congreso de Colombia (2003: 100). 
El tercer elemento es el espacio: en este aspecto la política indígena no ha podido avanzar y falta aún concretar los espacios de reunión a que tienen derecho las comunidades para su desarrollo cultural. El motivo es que tres de los cabildos solicitan a la administración municipal sitios de ladera en donde se encuentran algunas zonas de protección ambiental que ellos administrarían, asimismo, seguirían con las tradiciones y costumbres naturales y ancestrales; por otro lado, se encuentran dos cabildos que solicitan a la administración municipal lugares dentro del área urbana de la ciudad, ya que su economía se basa única y exclusivamente en la venta de todo tipo de artículos.

Adicional a esto, otro punto que toma la política indígena para la creación de un cabildo es el reconocimiento de la comunidad de origen o superior, ella tiene que emitir un aval de acuerdo al trabajo realizado en la ciudad, antes que el reconocimiento del Estado, y este en última instancia que les da el reconocimiento.

\section{La construcción de la paz desde la participación local}

La construcción de la paz en zonas de conflicto obligó a que las familias organizadas en cabildos y resguardos generaran condiciones de vida para todos sus integrantes, fue así como desde el Consejo Regional Indígena (CRIC) y la Asociación de Cabildos Indígenas del Norte del Cauca (ACIN), tuvieron que hablar con los representantes del Estado nacional para motivar y formar a todos los pueblos indígenas en actividades comunitarias y de participación, surgiendo así proyectos y planes de vida que hoy son un ejemplo de trabajo.

Todos los individuos son aportantes activos de los diversos procesos productivos, haciendo que su economía en desarrollo sea sostenible y armónica con la naturaleza, los planes de vida de los grupos de jóvenes indígenas son basadas en los ejercicios de vida, donde la capacitación, la investigación, los valores espirituales son el mayor valor agregado que tendrán las comunidades indígenas con el fin de proteger su cultura, autonomía, identidad, así como su unidad, su conciencia y por último el concepto de comunidad, la creación de la Universidad Indígena y las escuelas de enseñanza del derecho propio, la preservación de la madre tierra y otros programas expuestos. 
La paz desde lo local se fortaleció en el trabajo comunitario y liderado por médicos tradicionales y espirituales en conjunto con la comunidad, que desde sus necesidades planearon las posibles soluciones. Proyectos de resistencia civil pacífica como el Proyecto Nasa de Toribio y el Proyecto Global de Jambaló, el fortalecimiento de los procesos organizativos por cabildos y luego por resguardos, la concordancia de los planes de vida indígena con los planes de desarrollo nacional y la obtención, en las urnas, de municipios con cinco gobernantes indígenas, ${ }^{32}$ así como la opción becaria de Álvaro Ulcué Chocue para los jóvenes que cumplan con los requisitos exigidos por sus cabildos.

Las experiencias indígenas han sido expuestas ante la comunidad internacional junto con proyectos de desarrollo, logrando no solo la participación de organismos internacionales, sino haciéndose merecedores de premios y reconocimientos por su forma de organización, trabajo comunitario y desarrollo sostenible, así como por su resistencia pacífica.

\section{Consideraciones finales}

Las comunidades indígenas, una "minoría" con relación al censo nacional, representan una fuerte posición política, social, económica y cultural en la construcción del Estado-nación. Ellas, a diferencia de otros grupos sociales en Colombia son las que más demandan transformaciones en su calidad de vida, para conservar su cultura y tradición.

Las dimensiones histórico-culturales, políticas y económicas dentro de las comunidades representan el factor fundamental para su participación política y acción colectiva ante el Estado. Hay que tener presente que la participación de los pueblos indígenas es fundamentalmente enfocada para su comunidad, por eso la creación de mecanismos que beneficien el bienestar de las comunidades.

La lucha indígena por la reivindicación de los derechos es soportada y fundamentada bajo la normatividad. Lo que quiere decir que la lucha es legal y legítima, haciéndose sentir como parte del Estado. Es así como las etnias son una agrupación fundamental en la construcción del Estado colombiano. Por tanto,

32 Los cinco municipios que tienen alcaldes indígenas son Toribio, Caldono, Caloto, Silvia y Jambaló. 
tienen derechos y deberes por cumplir, aunque la legislación colombiana en los temas étnicos se encuentre muy débil.

Se comprendió la realidad del conflicto armado partiendo del diagnóstico realizado y aplicado a la población y el valle geográfico del municipio de Toribio-Cauca, logrando comprender el por qué de la existencia del cabildo urbano de Santiago de Cali.

Se estudió la existencia de derechos e instrumentos internacionales de los pueblos indígenas, así mismo como la aplicación de ellos y la debilidad evidente de la aplicación por instituciones del Estado a nivel central y por entidades, en suplir las políticas sociales de las comunidades observadas.

Se pudo analizar la forma de participación de las comunidades indígenas a partir de tres aspectos fundamentales: 1) las movilizaciones, 2) la conformación del cabildo urbano Yanacona en la ciudad de Cali y 3) la construcción constante de la paz desde lo local. Todas tres soportadas bajo programas implementados por ellos mismos para el aseguramiento de su cultura. Lo que deja en claro que la participación política no es a través de los partidos, sino a través de procesos colectivos y comunitarios.

Los partidos políticos étnicos no obedecen a una verdadera representación de la unidad étnica, sino a una serie de avales sin fundamento en los planes y políticas de las comunidades.

Partiendo de procesos comunitarios, se puede identificar cuál es el valor de la unidad social, así como el éxito de su organización, entendiéndose estos dos procesos como fundamentales para la conformación de los cabildos y resguardos.

\section{Bibliografía}

\section{Documentos}

1994 "Constitución Política de Colombia".

2002 "Derechos de los pueblos indígenas, oficina en Colombia del Alto Comisionado de las Naciones Unidas para los Derechos Humanos". Bogotá, agosto de 2002.

2003 "El conflicto, callejón con salida. Informe nacional de desarrollo humano Colombia". 
2003 "XI informe del defensor del pueblo, al Congreso de Colombia. Enero-diciembre 2003", pp. 95-100.

2004 "Instituciones de Colombia". En: Revista Credencial Historia. Separatas.

s/f "Educación con mujeres indígenas". Seminario técnico regional. Instituto Indigenista Interamericano, Oficina Regional de la UNESCO para América Latina y el Caribe (OREALC).

Hernández Delgado, E.

2004 "Resistencia civil, artesana de paz; experiencias indígenas, afrodecendientes y campesinas". En: Resistencias indígenas comunitarias del Cauca. Pontificia Universidad Javeriana.

Sánchez Botero, E.

2004 "Justicia y pueblos indígenas de Colombia". Unijus.

Vitonás, A.

2007 "Plan de desarrollo de Toribio. Periodo 2004-2007". Cauca.

\section{Artículos de prensa}

El Espectador (28/05/2005) "No podemos salir corriendo de aquí".

El Espectador (30/04/2005) "El inminente cerco de la guerra a Toribio".

El País (24/04/2005) "Toribio: una historia de resistencia a la guerra".

El Tiempo (24/04/2005) "A mí de Toribio no me sacan ni las bombas".

El Tiempo (29/04/2005) "Tacueyo teme ser un nuevo Toribio".

El Tiempo (04/05/2005) "Polémica: Consejos comunales sesgados".

El Tiempo (10/05/2005) "La guerra en el norte del Cauca".

El Tiempo (13/05/2005) “Tensión indígena con ejercito por capturas”.

El Tiempo (18/05/2005) "Un esquivo retorno a Toribio".

El Tiempo (20/05/2005) "Por supuestos vínculos con las FARC, ordenan captura de 200 indígenas Paeces".

El Tiempo (21/05/2005) "Editorial: el complejo lío del norte del cauca".

El Tiempo (13/06/2005) “Toribio dos meses después”.

Envío 12 de octubre/2013 - Aceptación 17 de diciembre/2013 